\title{
PROCESOS DE EMPODERAMIENTO Y LIDERAZGO DE LAS MUJERES A TRAVÉS DE LA SORORIDAD Y LA CREATIVIDAD
}

\author{
EMPOWERMENT AND LEADERSHIP PROCESSES OF WOMEN \\ THROUGH SORORITY AND CREATIVITY
}

\author{
Silvia Martínez Cano \\ Universidad Pontificia de Comillas
}

RESUMEN

Los desarrollos de los feminismos en la pluralidad nos retan a buscar nuevos procesos de empoderamiento y liderazgo para descentralizar los lugares de poder de las sociedades, donde las mujeres puedan liderar también la construcción de las culturas futuras. Se hace necesario, entonces, explorar algunos lugares donde las mujeres se sitúan en los márgenes de la realidad fratriarcal y proponen nuevas formas de existir tanto para las mujeres como para los hombres a través de liderazgos integradores y transformadores. Desde el análisis de las dificultades que se plantean en los procesos de empoderamiento de las mujeres, podemos acceder a estrategias como la gestión de la potencialidad de las mujeres, la generación de prácticas sostenibles en relación con la vida cotidiana y la preservación de las relaciones y los procesos nómadas enfocados a la construcción creativa de relaciones e identidades. Estas estrategias que pueden iluminar unas buenas prácticas feministas para la transformación de nuestros muchos mundos.

Palabras clave: liderazgo, empoderamiento, sororidad, sostenibilidad, nomadismo, circularidad.

\section{ABSTRACT}

The development of feminisms in plurality challenge us to seek new processes of empowerment and leadership to decentralize the places of power of societies, where women can also lead the construction of future cultures. It is necessary to explore some places where women are situated on the fringes of fratriarcal reality and are proposing new ways of existing for both women and men through integrating and transformational leadership. From the analysis of the difficulties that arise in the processes of empowerment of women, we can access approaches to strategies based on sorority circularity and creative nomadism: management of women's potential, the generation of sustainable practices in women. Relationship with daily life and the preservation of relationships and nomade processes focused on the creative construction of relationships and identities. These strategies can illuminate good feminist practices for the transformation of our many worlds.

Keywords: Leadership, Empowerment, Sorority, Sustainability, Nomadism, Circularity. 


\section{Introducción. ¿Tenemos autoridad las mujeres?}

Para hablar de liderazgo de mujeres, es necesario preguntarnos si las mujeres tenemos autoridad que pueda articular un liderazgo comunitario. La cuestión me lleva a una respuesta ambigua y a una toma de conciencia de las dificultades de las mujeres para hacerse un espacio en los lugares de participación y decisión.

Quisiera explicar esta ambigüedad mediante un ejemplo de la rica mitología griega, con la historia de Perséfone, hija de Zeus y de Deméter. Perséfone, también llamada Coré, es una joven doncella que vivía con su madre Deméter alejada de los dioses. Un día mientras ella recogía flores con otras diosas y algunas ninfas, Hades, dios del Inframundo, emergió de la tierra por una grieta y la raptó'. Cuando Deméter se dio cuenta de su ausencia, desesperada, cambió su ropa por la vestimenta de luto y comenzó a buscarla. Eran tales sus lamentos, que toda la tierra se estremecía. En esta búsqueda se encontró con Hécate, diosa de las encrucijadas ${ }^{2}$, que la consoló y decidió acompañarla. Ambas confirmaron gracias a Helios, que «todo lo ve», que había sido Hades. Deméter dejó de sostener la vida, impidiendo que ésta floreciera. Zeus pretendía convencerla con regalos para que cambiara de actitud, pero ella seguía lamentándose y exigía a Zeus la devolución de su hija antes de volver a hacer florecer la tierra. Cuando Zeus se cansó de aguantar sus lamentos, obligó a Hades a devolver a Perséfone. Hades puso una condición para su liberación. Perséfone no debía comer nada en el trayecto de vuelta a su casa. Sin embargo, el mismo Hades la engañó para que comiera seis granos de granada. Por este error ,fue obligada a volver un mes por cada grano de granada. Por eso, cuando Deméter y su hija estaban juntas, la tierra florecía hermosa de vegetación. Y durante los otros seis meses al año, cuando Perséfone volvía a los infiernos, la tierra se convertía de nuevo en un erial estéril. Hécate acompañaba a Perséfone al Inframundo, convirtiéndose en su compañera íntima.

Los griegos también cuentan otra faceta de Perséfone. Ella también era la más terrible Reina de los muertos, cuyo nombre no era seguro pronunciar en voz alta y a la que se referían como «La Doncella». En la Odisea ${ }^{3}$, cuando Odiseo viaja al Inframundo, alude a ella como

\footnotetext{
1 Deméter, diosa de la agricultura y diosa nutricia de la tierra verde y joven, ciclo vivificador de la vida y la muerte, y protectora del matrimonio y la ley sagrada. Cfr. Jean-Pierre Vernant (1991) Mito y religión en la Grecia antigua, Barcelona, Ariel, pp. 65-67.

2 Una diosa de procedencia no griega pero que se adscribe el panteón griego como hermana de Artemisa y Apolo. Diosa de los páramos salvajes y de los partos y más tarde diosa de la hechicería y los fantasmas, adquiere también el atributo de la diosa de las fronteras, también entre las del mundo y el inframundo. Se ponían imágenes de Hécate en las fronteras como protección frente al peligro. También en las puertas de las casas y ciudades. Con el tiempo, al estar asociada al alejamiento de espíritus malignos llevó a la creencia de que ofender a Hécate también los atraía. Así surgieron las invocaciones a Hécate como gobernadora suprema de las fronteras entre el mundo normal y el de los espíritus. Cfr. Burkert, Walter (2005) Cultos mistéricos antiguos, Madrid, Trotta (1987).

3 Homero, La Odisea, Madrid, Gredos, capítulo IX.
} 
«Reina de Hierro». Ella escondía extraños ritos iniciáticos de regeneración de los misterios eleusinos ${ }^{4}$, que prometían la inmortalidad a los participantes: una inmortalidad en el mundo subterráneo de Perséfone, en un banquete con los héroes bajo su aterradora mirada.

Lejos de hacer un análisis de la mitología griega, lo que intento mostrar es que las artes de las mujeres para obtener autoridad pasan normalmente por otros lugares que no son los masculinos. Las mujeres tenemos poder, tenemos autoridad, pero de una forma ambigua, desde lo desesperado, desde lo escondido, desde las periferias.

La desesperación de Deméter de no tener quién la escuche nos recuerda nuestros lamentos cuando vivimos oprimidas, silenciadas o violentadas. La desesperación de Perséfone de tener que vivir y servir con el que nos somete, nos humilla, nos ignora o simplemente no nos comprende nos recuerda la gran cantidad de situaciones que ponen a las mujeres en situaciones de pasividad ante un sistema opresor masculino. Nuestro mundo está hecho para palabras masculinas, que hablan del poder, de la fuerza o de las alianzas entre poderosos. Normalmente las mujeres no tienen el poder para decidir sobre sus vidas, y este poder, se va conquistando a duras penas a lo largo de la vida, como un proceso lento, de autoconciencia de las propias limitaciones y dificultades. Algunas ni siquiera son conscientes de esta realidad. Se hace a través de la protesta y la denuncia, a través de los lamentos y denuncias, como Deméter. Deméter no paró hasta conseguir que los dioses se movilizaran para ayudarla, aunque fuera por aburrimiento. Así son las mujeres coraje, las madres de la Plaza de Mayo, las mujeres que defienden a sus hijos, o aquellas que defienden a otras compañeras y salen a la calle a manifestarse.

Otras veces las mujeres conquistan el poder sacando lo más oscuro de sí mismas, su mirada terrible, como Perséfone. Se hacen con el poder moviéndose en territorios invisibilizados, en segundas filas, desde conspiraciones indirectas, donde nos convertimos en fieras terribles, obligando a los hombres y a otras mujeres a pasar por nuestros deseos como Perséfone, y así obtener derechos y beneficios.

Por último, las mujeres en estos momentos de desesperación, establecen ciertas alianzas entre ellas que las permiten sobrevivir en un mundo adverso a sus problemas, y que muchas veces les niega la ayuda que necesitan. Cómo Hécate se solidarizan unas con otras, empatizando recíprocamente con el propio ajeno.

4 Los misterios eleusinos eran ritos de iniciación anuales al culto a las diosas Deméter y Perséfone que se celebraban en Eleusis (cerca de Atenas), en la antigua Grecia. De todos los ritos mistéricos celebrados en la antigüedad, estos eran considerados los más importantes. Los ritos de culto se guardaban en secreto, incluyendo promesas de poder divino y recompensas en la otra vida. Cfr. Burkert, Walter (2005) Cultos mistéricos antiguos, Trotta, Madrid, pp. 59-62. 


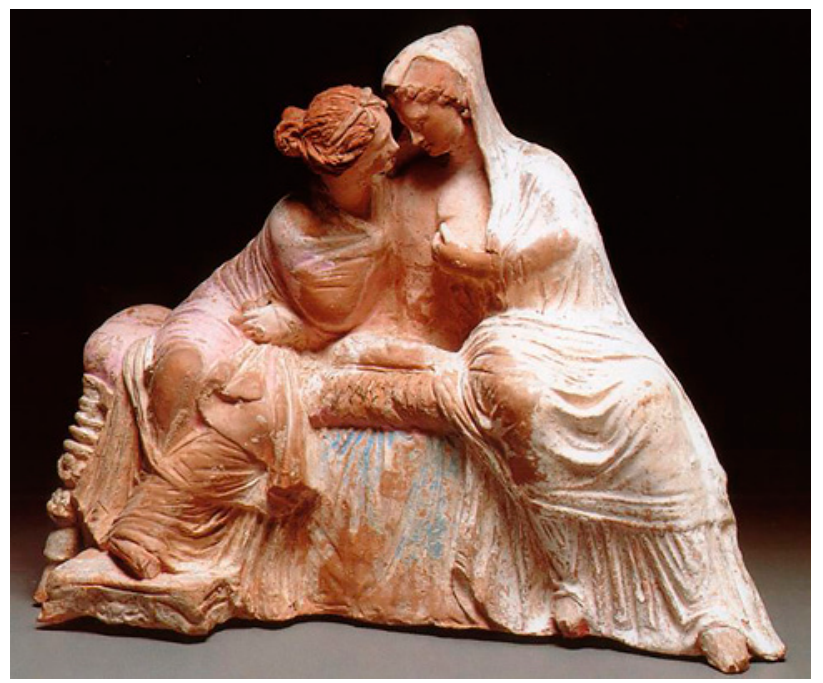

Imagen: Demeter y Perséfone. British Museum, Londres, ca. 100 a.C.

Considero que esta no es la mejor manera de obtener el poder, porque es un poder desesperado, poco reflexivo, agresivo, que viene de las necesidades que surgen de las experiencias de dolor y no de la propia experiencia liberadora de los cuerpos y las vidas de las mujeres. Vamos, por tanto, a realizar un pequeño recorrido por las dificultades que tienen las mujeres a la hora de conquistar su propia autonomía para luego detenernos en los procesos que las empoderan de forma liberadora, haciéndose sujetos de su propia historia. Con ello localizaremos aquellas estrategias que las empoderan y aquellas actitudes que favorecen los liderazgos femeninos sociales, enfocados a una transformación estructural de nuestros lugares de co-habitación.

\section{El liderazgo desde las periferias. Dificultades}

En unas sociedades como las nuestras, plurales, diversas, los liderazgos de las mujeres pueden quedar ocultados por la estructura patriarcal social. Pero también pueden ser germen de transformación, pues quedan alejados de los núcleos de poder y establecen unas relaciones dinámicas evitando, en muchas ocasiones, los elementos normativos.

La visión patriarcal de la vida sólo entiende de normas y leyes. Necesita de un sistema de dominación/sumisión para sobrevivir. $Y$ en él se entrelazan las alianzas entre 
los poderosos, normalmente hombres blancos, para justificar y sostener el «orden» social y cultural. Se establecen fratriarquías, «el gobierno de los hermanos» (Rodríguez, 2015: 2223), que controlan social y culturalmente nuestras vidas: los comportamientos, las creencias y pensamientos, los cuerpos, las relaciones.

Las mujeres están normalmente fuera de estos círculos de alianzas. Establecen otros pequeños círculos de relaciones que están ligados normalmente con la resolución de las cuestiones pragmáticas de la vida cotidiana, pero difícilmente tienen espacio para entrar en círculos más amplios de participación social. No tienen tiempo, lo emplean en los hijos, el marido, la familia, el trabajo... Habitan en las periferias de las sociedades y del poder que se ejerce en esas sociedades. Son cuerpos que se encuentran en los «no lugares», esta expresión de Michel Foucault (1967) que denomina los lugares que no interesan, que son ocultados: cárceles, burdeles, hospitales, cementerios... se podría añadir desde una perspectiva feminista otros «no lugares», como los hogares rotos por la violencia o en situación de precariedad, los trabajos sin contrato, los barrios empobrecidos, los trabajos no cualificados, etc. En todos ellos, las protagonistas son las mujeres como sujetos receptores de gran cantidad de problemáticas que limitan su situación y su capacidad de decisión y acción. Estos lugares se ocultan, porque son diferentes de una realidad construida idealmente, a través de una política patriarcal mediática y agresiva, que representa una imaginería social sin dolor, sin conflictos, sin problemas.

Los «no lugares» no existen en nuestra globalización, quedan en los rincones más oscuros y olvidados, son periferias sin capacidad de liderazgo, sin autoridad para intervenir en el desarrollo social. Salirse de nuestros pequeños círculos y querer decidir por nosotras mismas conlleva no pocos sacrificios por un lado y no pocos sufrimientos por otro. Somos castigadas como Perséfone, ninguneadas como Deméter. Así sucede con los cuerpos de las mujeres que son ignorados, insultados, incluso maltratados o violentados.

Para el sistema de alianzas fratriarcales, la única vía es que las periferias soporten este entramado de problemáticas de una forma pasiva, como única forma posible de existir. Su estrategia consiste en debilitar a los sujetos femeninos de estas periferias, para que no desarrollen autoridad sobre sus vidas y sobre la vida de los demás. Es frecuente encontrar a mujeres que repiten como un mantra "yo no puedo», «no es posible para mí», «no me siento capaz», «no lo haré bien», ... creencias que se interiorizan formando un sustrato identitario femenino que anula nuestras potencialidades en lo personal y lo comunitario. Estas herramientas biopolíticas (Hardt y Negri, 2002: 20) han sido progresivamente puestas al servicio del poder patriarcal: «El control de la sociedad sobre los individuos no se efectúa solamente a través de la consciencia o de la ideología, sino también en el cuerpo y con el 
cuerpo. Para la sociedad capitalista, es la biopolítica lo que más cuenta: lo biológico, lo somático, lo corporal» (Foucault, 1999: 210). Estamos ante una red compleja de justificaciones y dominaciones corporales que también entre nosotras nos imponemos, contribuyendo a nuestra invisibilidad. El control de las distintas facetas de la vida, administrando lo que somos y lo que decidimos, dificulta distinguir lo que es verdad y lo que pertenece a lo construido socialmente, especialmente para las mujeres y su invisibilización. Vela las injerencias del sistema en la propia vida (cuerpo/identidad) y normativiza lo biológico creando categorías corporales e identitarias a las que ajustarse. De esta manera, se administra a los sujetos marcándolos, definiéndolos y discriminándolos. A las mujeres las fragmenta porque debilita las relaciones que establecen, y ello contribuye a construirlas como sujetos vulnerables y frágiles en espacios de marginalidad (Fernández, 2010: 53).

En el ámbito del liderazgo, quisiera mencionar dos mecanismos de exclusión que, entre otros, dañan y justifican este ocultamiento de las mujeres en los espacios de decisión. El primero es el uso de la palabra en el espacio público y privado. Se trata de un poder ejercido en formas institucionalizadas, donde se establecen unas jerarquías en cuanto a la articulación y la veracidad de la palabra, como capacidad de describir e interpretar el mundo y los sujetos que viven en él. El lenguaje, desde una lógica fratriarcal, construye su propio discurso de «segundas clases» donde la palabra de las mujeres «vale menos» que la palabra de los hombres. Así, establece servidumbres y marca lo que las mujeres pueden o no pueden decir. Excluidas de la posibilidad de describir el mundo, se silencia a las mujeres. El uso del lenguaje es un privilegio y un reconocimiento en la participación pública y en la elaboración de las normas de convivencia social (Fraser y Honneth, 2006). El hecho de negar a las mujeres este privilegio, ya sea por su silenciamiento o por la minusvaloración de la palabra dicha, implica un recorte de la identidad propia y un desplazamiento hacia los «no lugares» sociales.

El segundo mecanismo de exclusión que va a estar implícitamente en este texto es la organización del espacio (Vianello y Caramazza, 2002: 38-40), como un constructo histórico, que sitúa y clasifica a los sujetos otorgándoles mayor o menor dominio sobre la esfera social en función del lugar ocupado. En el reparto territorial las mujeres ocupan espacios más pequeños y menos significativos en la cartografía social. Las mujeres al ocupar pocos espacios relevantes, tampoco desarrollan la capacidad de apropiarse de otros espacios ni de controlar los espacios propios con propuestas creativas de gestión y visibilización de los mismos. La escasez de espacio y tiempo propio y social (Woolf, 2003) desprovee de derecho a disentir y a intervenir en las decisiones sociales, desarticulándose el binomio poder/libertad, a la vez que limita la interacción social, por lo que reduce la visibilidad y el 
reconocimiento social de las mujeres. Así, los modelos de liderazgo reconocidos de mujeres son menores y su influencia también, tanto para hombres como para mujeres.

Para combatir este control y ocultamiento de las mujeres, al igual que Perséfone, Deméter y Hécate, las mujeres han desarrollado procesos de resistencia y de empoderamiento que contribuyen a denunciar las estrategias de opresión de las mujeres en sociedades fratriarcales y a generar procesos creativos de apropiación de espacios tanto personales (corporales/identitarios) como sociales. Por ejemplo, el activismo en asociaciones feministas o pertenencia a colectivos de barrio con fines sociales o culturales que abren espacios de dialogo e intercambio en mujeres adultas o el cuidado del tiempo personal y de amistad al que dedican las mujeres jóvenes con otras mujeres...

En estos ejemplos $u$ otros, el empoderamiento debe protagonizar la reflexión sobre los estereotipos femeninos y masculinos, su crítica y desconstrucción. Pero no solo eso, sino avanzar repensando el concepto de política desde otros parámetros nuevos para la convivencia e interrelación social (Harcourt, 2011: 254). Para ello, es necesario una búsqueda de un lenguaje propio que articule la diversidad femenina y sus relaciones sororales como alternativa a los discursos dominantes (Fernández, 2010: 49), un lenguaje que pueda incorporarse a las categorías del diálogo social y articule una nueva cosmovisión cultural. La búsqueda de espacios de diálogo donde se contrasten las necesidades y las demandas de unos y otras será, entonces, prioritario para la activación de la producción de consensos políticos en lo social, que a la vez los legitime y los visibilice.

\section{Procesos de empoderamiento desde la autonomía personal}

Vamos, pues, a analizar los procesos de adquisición de autonomía personal, que pasan por el descubrimiento de una interioridad rica. Esto solo puede suceder si realizamos un trabajo personal de conocimiento, pero también de transformación de ciertas rutinas adquiridas que nos dificultan el tener el control sobre nuestra vida.

\subsection{Hacia la autonomía personal}

En los procesos de empoderamiento, el horizonte está puesto en la adquisición de la «autonomía personal». La autonomía personal es una consciencia personal de que mi persona es algo valioso, no sólo para una misma, sino como sujeto activo en la sociedad. Esta consciencia reconoce la propia autonomía personal en el territorio de las emociones y de las decisiones. Es decir, ejercer la propiedad sobre el cuerpo, la psicología, las decisiones 
y sobre la vida propia en general. De esta autonomía emana un poder interior que me impulsa a tomar el control no sólo de mi vida. Esto supone independencia de otros, separada del condicionamiento que ejerce el poder fratriarcal en las mujeres (Gil, 2011: 45). Por tanto, autonomía también es poder, un poder interno que se construye poco a poco, a través de la reapropiación de la vida, pero también en cooperación con las personas que nos rodean (Gil, 201 1: 46), porque supone un reordenamiento y creación de relaciones sociales satisfactorias y enriquecedoras.

Para ello, hace falta un aprendizaje de ese ejercicio de poder sobre la vida misma que no está exento de una lucha cotidiana por el espacio personal, como decía antes haciendo referencia a Virginia Woolf (2003). A este proceso complejo y profundo, lo llamamos proceso de empoderamiento. Si en décadas anteriores, la autonomía personal se centraba en adquirir una autonomía colectiva frente a los sistemas políticos (años 70) y en adquirir una autonomía sobre el propio cuerpo y su identidad (años 80-90), hoy preocupa una autonomía que movilice la capacidad de los sujetos de desear, cooperar y crear más allá de las normas económicas y culturales que nos someten y desarticulan como protagonistas de la propia historia (Rodríguez, 2015: 44-49). No cabe duda que la autonomía pasa por la propia identidad y el aprendizaje de sus relaciones con los otros y otras. Por eso, el proceso se inicia en la autoestima personal y pasa por una asertividad práctica que articula, junto con la anterior, la autonomía propia.

\section{a) Autoestima}

El primer paso del empoderamiento es la construcción de la autoestima en la vida cotidiana. Sin una autoestima trabajada no es posible ser autónoma. Es el elemento principal que articula los procesos de empoderamiento. La podemos definir como la valoración que hacemos de nosotras mismas a partir de las experiencias que hemos vivido a lo largo de la vida. En palabras de Marcela Lagarde es «una experiencia ética de fidelidad a una misma: una experiencia que fluye y se transforma en permanencia (...). Construir la autoestima es vivir, de hecho, bajo las pautas éticas del paradigma feminista, es ser libre» (Lagarde, 2000: 32). Aprender a valorarse, amarse, aceptarse tal como una es, requiere un entrenamiento. Este ejercicio no es fácil. Está en relación directa con el entorno en el que una vive. A veces la autoestima viene disfrazada de otras actitudes. A veces hay mujeres que parece que tienen una autoestima muy elevada, sin embargo, esa máscara esconde una autoprotección, ya que la persona fue dañada o manipulada anteriormente, y preserva de este modo su intimidad para impedir que otras personas o situaciones vuelvan a causarle dolor (Lagarde, 2000: 23). Son más frecuentes las mujeres que muestran una autoestima baja en el día a día. Tienen 
interiorizada su condición de inferioridad con respecto a los hombres. Esto tiene que ver con la organización cultural de género donde prevalecen las jerarquías y minusvaloraciones de lo tradicionalmente femenino, entorpeciendo el crecimiento interior de las mujeres y su reconocimiento público (García-Mina, 2003: 60).

Las mujeres alimentan la baja autoestima repitiendo afirmaciones que reciben de la cultura fratriarcal: «no me lo merezco», «no soy suficientemente buena», «es demasiado para mí», «no me veo capaz de...». Estos «autodiálogos» obstaculizan las iniciativas de las mujeres, haciéndolas más pasivas, menos arriesgadas y más conformistas. Las principales creencias en los autodiálogos de las mujeres son la necesidad de aceptación, la indefensión, la irresponsabilidad emocional y el autosacrificio (Cardeñoso, 2007: 36-37). Todos ellos contribuyen a una baja autoestima que merma las posibilidades de autonomía personal. El proceso de cuidar la autoestima conlleva crear mecanismos personales que desbloqueen de lo negativo que le impide a la persona hacerse con el control de sí misma. Primero, aceptarse tal como es con sus luces y sombras, siendo consciente de las limitaciones que puede tener; estas limitaciones pueden ser educadas para mejorar en la autonomía cotidiana; y las virtudes que se tengan se deben desarrollar y mostrar para beneficio personal y de los que la rodean. Segundo, aprender a amarse con comprensión, sin autocompadecimiento, con alegría, sin resentimiento. Esto permite ir realizando cambios permanentes que liberan a la persona del sentimiento de incapacidad que la lleva al miedo y a la frustración.

\section{b) Asertividad}

Entre la autoestima y la autonomía personal hay un paso intermedio que permite acceder a la autonomía personal. Ese paso es la asertividad, es decir, adquirir la capacidad de decir las opiniones o sentimientos propios sin miedo o culpabilidad y de enunciar las propias opciones. La asertividad influye profundamente en las relaciones sociales. Las personas asertivas son más alegres, más resolutivas, interaccionan mejor con las personas que tienen alrededor. Adquieren una determinación que les hace desarrollar una autoconfianza más sólida. La clave para una asertividad sana es la empatía, es decir, ser capaces de distinguir entre lo que la persona dice y nuestras propias reacciones o juicios. En este sentido una buena empatía construye una relación asertiva donde es fácil comunicar las diferencias entre personas, respetando la heterogeneidad también en el ámbito del comportamiento.

La asertividad devuelve a las mujeres el derecho a ser tratadas con respeto y dignidad. Con ella pueden expresar sus sentimientos y emociones sin miedo a sentirse atropelladas por la creencia masculina de que deben ser corregidas o influenciadas. Y al encontrarse de nuevo 
con estas situaciones desarrollan la capacidad de ejercer el derecho a cambiar, y a decir «no» sin sentir culpabilidad por romper el silenciamiento que se las impone. Así adquieren independencia y, por otro lado, responsabilidad, es decir, se hacen cargo de sus problemas, sin esperar la aprobación de otros o que alguien venga a «rescatarlas».

\section{c) Autonomía personal}

Autoestima y asertividad completan un proceso personal que puede situar a las mujeres en contextos de nuevas relaciones sociales y personales. En él se adquiere independencia, libertad, autodeterminación, autogobierno y libertad personal (Shinoda Bolen, 2014: 61). Ser autónoma es ocupar un lugar en el mundo, como algo propio, necesario, desde la singularidad personal. Vivir consciente de que los condicionamientos a los que viven sometidas las mujeres no están por encima de lo que sienten, viven y deciden. Esto visibiliza las propias limitaciones, pero también los objetivos que se desean. Obliga, así, a revisar las creencias personales. ¿̇Es necesario la aprobación de otros? ¿̇Es posible una articulación entre el espacio personal y el espacio de los otros? $\dot{\partial}^{Y}$ es posible en otros círculos sociales?

\subsection{Estrategias en el empoderamiento}

Los procesos de empoderamiento llevan a las mujeres del «no puedo» al «soy capaz». Es decir, ayudan a entrenar la autoestima y la asertividad para aprender a vivir desde la autonomía personal. En ese proceso se adquiere poder no solo sobre la propia vida, sino también sobre el entorno que circunda e interactúa con la persona. Se ensancha el espacio ocupado tanto físico como subjetivo. Se manifiesta el atrevimiento de salir a otros espacios de participación con la seguridad de que las aportaciones que se puedan hacer no sólo benefician lo personal, sino también a las dinámicas sociales. «Empoderamiento» es un anglicismo que tiene que ver con la adquisición del poder y no con la imposición del poder. El empoderamiento es la adquisición de la conciencia de «ser capaz de», o sea, salir de la sumisión del autocompadecimiento y tomar la iniciativa en las problemáticas de los entornos sociales que nos rodean (Rowlands, 1995: 103).

\section{a) La insumisión como estilo de vida}

Los procesos de empoderamiento conllevan abandonar ciertos hábitos para obtener cierta autonomía personal y empoderarnos. Estos hábitos, entendidos como la práctica del «hacer» foucaultiano (Meloni, 2012: 224), están arraigados en la imaginería cultural, 
interiorizados en la disciplina de la socialización, y son consecuencia de creencias que nos someten y subordinan a los hombres. Un gasto de energía inicial en los procesos de empoderamiento debe ir orientado a cultivar una actitud de no sometimiento, es decir, adoptar la insumisión como estilo de vida (Yániz, 2007: 214-215). Esta actitud de vigilancia ante lo que nos rodea nos ayuda a identificar aquellos roles o actitudes impuestas que no queremos, pero asumimos bajo la presión del entorno. Los hábitos debilitan la visibilidad de las mujeres en el medio social y las restan poder. Algunos de estos hábitos son:

- Disculparse frecuentemente: disculparse demasiado o cuando es innecesario disminuye el poder y nos subordina a la otra persona.

- No asumir el mérito de las propias ideas o creatividad: defender la creación de ideas, acciones, etc., favorece la visibilidad femenina en los grupos humanos y muestra sus capacidades y habilidades. En este sentido, es importante desterrar la idea de que la autopromoción es vanidad. Al contrario, en su justa medida, es una habilidad para el liderazgo y ayuda a cambiar la mirada de la comunidad.

- El rechazo a usar influencias propias: el poder viene en relación a los objetivos, las propuestas y las relaciones que se establecen entre sujetos. Construir relaciones beneficiosas entre los que comparten actividades favorece una reciprocidad más igualitaria y sitúa a las mujeres en lugares más visibles en el mundo.

- No aprovechar las relaciones: las mujeres tienden a hacer favores a los demás, pero en muchas ocasiones ven mal pedirlos o pedir algo a cambio. Como si no fueran dignas de recibir de los demás. Esta estrategia, en su justa medida, es una habilidad que fomenta el intercambio y el liderazgo. Favorece a equilibrar el pedir y el dar, exigir lo que se quiere y lo que se necesita y dar desde una mirada solidaria.

- Desear ser queridas por todos: es imposible caer bien o satisfacer a todo el mundo. La amabilidad con las personas debe ir acompañada de la eficacia para poder empoderar a las mujeres. Si las mujeres se centran en agradar a otros, estarán sometidas a sus deseos. Al combinar amabilidad con eficacia, se trazan caminos propios que dialogan en la diferencia y enfrentan los conflictos cuando se producen desencuentros o desprecios por las decisiones tomadas.

La estructura fratriarcal social considera que si una mujer usa este tipo de estrategias es egoísta, ya que «la mujer» debe poner su vida al cuidado de los demás. Los círculos en los que vivimos promueven muchas veces este imaginario, situando las decisiones de las mujeres en una encrucijada de indefinición y culpabilidad (Sáenz de la Fuente, 2006: 88). La culpabilidad las presiona para que se sometan al rol femenino fratriarcal de los cuidados. Sin embargo, cuando una mujer se abre a sus potencialidades y talentos, y se hace 
presente en los espacios de participación social, colectivos culturales y sociales, activismo, asociacionismo, etc., el empoderamiento se transforma en un beneficio social.

\section{b) Romper para liberar}

Cada mujer debe buscar sus propios procesos de empoderamiento. Es un trabajo personal que conlleva un esfuerzo de autoconocimiento de la propia subjetividad, de cómo se construye e interacciona con el entorno (Brah, 2004: 133). También de un devenir autoconsciente que traspase las fronteras más allá de lo que impone la sociedad (Braidotti, 2005: 111 1). Valorar sus intereses, que no tienen por qué estar solo centrados en ella misma, sino que pueden tener que ver con el compromiso con otras personas o acciones.

El empoderamiento personal puede empezar por la liberación de multitud de cargas personales. Son cargas psicológicas, afectivas, sociales y personales que se le han adjudicado históricamente a las mujeres, entre ellas la distribución de roles, las funciones en el cuidado de la comunidad y la familia, los esquemas antropológicos en el discurso y en la praxis de la identidad, los prejuicios en las relaciones personales y hasta las limitaciones que las articulaciones del género (en perspectiva fratriarcal) se les imponen.

Por tanto, un trabajo fundamental es localizar experiencias y cargas que se llevan encima y dificultan una confrontación personal positiva. Maltratos, humillaciones, relaciones disfuncionales de pareja; sentimiento de soledad, autoestima deteriorada; presión de los reclamos de la familia, amigas, amigos; competencia y enfrentamiento con otras mujeres; logros que no satisfacen o que no se sienten como propios sino como obligados; sensación de estar en deuda con todos; vacíos permanentes en el proyecto vital...

Detectar estas problemáticas puede ayudar a romper con algunas de ellas. Esto quiere decir que se acepta que estas situaciones estén en la vida personal, pero sin dejar que monopolicen lo cotidiano, sin dejar de ser ese sujeto que se construye y modela en la interacción (Meloni, 2012: 224). El rompimiento implica rechazar el chantaje psicológico y emocional de los discursos interiorizados de estar al servicio de todos sin condición ninguna. El rompimiento significa proteger la propia vida para encauzarla hacia una identidad propia, construida desde la crítica, pero también desde la propuesta y el diálogo (y no la imposición) con otras y otros.

\section{c) La afirmación y el liderazgo interno}

Un ejercicio interesante es, también, otorgarse poder y legitimidad a una misma, sin esperar la aprobación de otros, sobretodo de los hombres que creen tener el poder. Con 
ello, se crea un poder no opresivo que puede ser compartido con otras mujeres y que puede influir en sujetos que ejercen el poder entendiéndolo como dominación. En la interacción se visibiliza una negativa ante el control de la vida de las mujeres. Se rechaza, así, la obligación de soportar todo tipo de sufrimientos en la vida cotidiana, que invalidan la subjetividad personal dejando a las mujeres en minoría de edad (Barroso, 2007: 184).

Para llegar a esta autoridad personal es importante comprometerse en determinados cambios personales en la autopercepción, estabilidad, control, fortaleza y sociabilidad. Cambiar en la forma de verse a una misma, ordenar y dar prioridad a unos deseos frente a otros, contrastar las expectativas de los demás con las expectativas propias y el principio de realidad, renovarse cada cierto tiempo, conocer la personalidad propia y disfrutar de ella, hacer valer la voz individual en las situaciones que lo requieran, entrenar la asertividad en las relaciones personales...

Otorgarse poder implica recuperar el control y el poder sobre la vida cotidiana y reivindicar que «lo personal es político». Esto quiere decir que en los ámbitos comunitarios habrá que deconstruir aquellos hábitos que no reparten el poder de forma ecuánime entre los participantes y proponer nuevas relaciones democráticas.

\section{Prácticas de liderazgo creativo}

Las mujeres empoderadas pueden constituirse como líderes de su comunidad, haciendo una contribución de dignidad, de acto de justicia que restituye lo postergado en la historia en contra de las mujeres. En cada logro que obtiene una mujer subyace una conquista. Una conquista que es una gota en un todavía océano de iniquidad laboral, violencia doméstica, explotación de menores, pobreza, analfabetismo, discriminación social... Para las mujeres que alcanzan el liderazgo comunitario, un objetivo imprescindible es ayudar a otras a no ser víctimas. La solidaridad entre mujeres obliga a la sororidad, acompañar a otras.

La práctica de un liderazgo creativo significa promover en las mujeres la capacidad de asociar ideas, liberando miedos y apostando por sus derivas, de tal manera que obtengan soluciones más originales y contextualizadas para las problemáticas a las que se enfrentan. Si las mujeres recorren procesos de empoderamiento, personalizando en un estilo propio de participación e influencia social en sus barrios o entornos, estamos ante una diversidad creativa de cauces de comunicación social. Un liderazgo creativo tiende a trazar redes de participación, en función de los contextos y las necesidades. Construye puentes de diálogo, descubre necesidades y denuncia desigualdades... impulsa la cultura de la equidad y la sororidad. Y a la vez construye un entendimiento recíproco entre hombres y mujeres para forjar equilibrios incluyentes, en distintas direcciones, que transformen la sociedad. 


\subsection{El cómo del liderazgo de mujeres}

Vamos por tanto a revisar los distintos elementos que conforman el liderazgo femenino, es decir, la formación de una masa crítica de mujeres que piensa como sujeto colectivo activo que se reúne en círculos sociales, empoderando a otras mujeres para su participación en las redes sociales. Este liderazgo se realiza desde un trabajo colectivo, pero también desde un acompañamiento de las unas a las otras soñando en un futuro. Es decir, implica una «ética de la solidaridad» (Valcárcel, 1997), un apoyo mutuo para aquellas que estén llevando a cabo acciones por la emancipación feminista en cualquier ámbito social o económico.

\section{a) De la minoría grupal a la masa crítica}

Normalmente en los lugares de participación públicos suele haber minorías de mujeres. A veces se da lo que llamamos minoría simbólica, que es la presencia de una o dos mujeres, en las que se focalizan todas las cuestiones que tienen que ver con «la mujer», generalizando de tal manera que se convierte en un remanente teórico.

Otras veces la minoría es algo mayor, pero no tiene un peso significativo en la parte operativa del grupo. La posición de estas mujeres en los distintos grupos sociales está muy influida por otros factores que determinan las condiciones de las mujeres en general: la división del trabajo por sexos, la socialización de los niños y de los adultos, las actitudes hacia las mujeres, la distribución del poder entre los sexos en la vida social y familiar, etc. Esto nos dice que su presencia está dificultada por una cantidad de problemas a los que las mujeres se enfrentan en tales posiciones. La tensión de las relaciones en un grupo de iguales dominado por varones, influye en la participación y liderazgo de las mujeres y su capacidad para efectuar cambios, tanto personales como grupales. Algunos de los problemas que podemos mencionar son:

- Baja visibilidad en las discusiones y tareas del grupo. Frecuentemente ignoradas en sus aportaciones.

- Estereotipamiento de las mujeres.

- Conflictos de papeles a la hora de liderar una acción o un grupo en general.

- Carencia de autoridad legitimada.

- Exigencia mayor en las mujeres para ser aceptadas en el grupo. Pero si la mujer es demasiado competente, se vuelve una amenaza.

- Adaptación inconsciente de las mujeres al dominio de varones.

- Carencia de aliados en los espacios de poder. 
- No consideración de las obligaciones familiares, maternidad, hijos, etc., como algo a tener en cuenta en el grupo.

- Acoso sexual.

- Tensión psicológica en las relaciones y las decisiones.

- Alta tasa de deserción de los lugares de decisión.

Cuando una o varias mujeres son capaces de incorporar a otras mujeres a la minoría y comienzan a reforzarse unas a otras, la minoría se va volviendo suficientemente fuerte como para empezar a influir en la cultura del grupo. Las alianzas en el interior del grupo minoritario pasan de posibilidad a realidad. Se comienzan a ver como sujetos individuales, diversos y respetados.

Hasta entonces el objetivo había sido la visibilidad, ante la frecuente indiferencia de los varones. Pero en este momento es cuando se comienza a tener como objetivo un cambio en las relaciones de poder. Es aquí cuando podemos hablar de «masa crítica».

El concepto de «masa crítica» no solo tiene que ver con el aumento de mujeres que establecen alianzas entre ellas, normalmente en torno a un $30 \%$, sino de un salto cualitativo en las relaciones sociales, que influyen en las decisiones y operatividad es de los grupos o comunidades, monopolizadas por una mayoría masculina. Las influencias de una minoría critica permiten a otras del grupo sometido usar recursos grupales para mejorar su propia situación y la de la minoría a la que pertenece.

La minoría es capaz ahora -si lo desea- de acelerar los cambios personales y grupales y de hacer frente a los problemas que antes enunciábamos. Porque hay que ser conscientes que no siempre una gran minoría, desde el punto de vista cuantitativo (más del 30\%), es una masa crítica, es decir, se constituye como grupo y lucha por la transformación comunitaria. Que la masa de mujeres se convierta en crítica depende a veces de los factores externos y de las estructuras y su capacidad de diálogo (Flesher, 2015: 7-8).

En algunas ocasiones las mujeres se enfrentan unas a otras, en una colaboración con las alianzas fratriarcales que las restan apoyos. Sólo involucrando a mujeres y hombres en alianzas que apoyen los liderazgos y la visibilidad de las mujeres, podemos conseguir cambios en las estructuras sociales.

\section{b) Características del liderazgo femenino}

El liderazgo femenino surge frecuentemente dentro de la masa crítica. A veces una masa crítica de mujeres surge en torno a una mujer que ha hecho un proceso personal de 
empoderamiento y ha ido aliándose con otras mujeres y ayudándolas a hacer procesos similares. Otras veces un grupo de mujeres, a veces muy pequeño, comienza a caminar por el proceso de empoderamiento apoyándose las unas a las otras. Y en este espacio cuidado, surgen liderazgos femeninos que después tendrán repercusión no solo en el propio grupo sino también en otros espacios sociales o eclesiales.

Las teorías sobre el liderazgo del sociólogo Robert House (1971) fueron el punto de partida para un estudio a fondo de los liderazgos en los distintos grupos humanos. House y su colega Mitchell distinguieron cuatro modelos de liderazgo: el liderazgo de apoyo, el liderazgo directivo, el liderazgo participativo y el liderazgo orientado al logro. Reflejaban tipos de conductas que adoptaban los líderes eficaces. Sin embargo, son modelos que están basados en los comportamientos masculinos. En los años noventa estos modelos clásicos comenzaron a tener en cuenta otros aspectos que no sólo los puramente directivos, incluidas las diferencias entre géneros (House y Mitchell, 1974). Según $M^{a}$ Amparo Ramos, las mujeres desarrollan más su liderazgo trazando vínculos relacionales y emocionales, incrementando la potencialidad del grupo e introduciendo cambios y diseñando acciones para afrontar los acontecimientos sociales. Parece que las mujeres se ajustan más al modelo de liderazgo «transformacional», esto es, un liderazgo que potencia la iniciativa y promueve cambios en cada miembro del grupo, para que se desarrolle como persona (Ramos, 2005: 100-103). Se produce una relación de respeto y admiración, que potencia el liderazgo de otros. Y todos los miembros del grupo aumentan su compromiso con el quehacer del grupo, al experimentar un incremento de la autoestima y de apoyo.

El liderazgo femenino es un liderazgo que tiende a trabajar desde lo cooperativo y lo sororal (Ramos, 2005: 108-114) aunque no debemos generalizar esta afirmación (MedinaVicent, 2014: 277), siendo conscientes de que los matices en el liderazgo de mujeres superan una afirmación ontológica del liderazgo femenino. Sin asociarlo de forma natural a las mujeres, podemos decir que es un liderazgo:

Más asertivo, porque conecta con flexibilidad las capacidades empáticas y las habilidades de comunicación interpersonal. La colaboración y el consenso son claves para la consecución de objetivos.

Más abierto al cambio y a la innovación, porque suele ser menos rígido o dogmático que los modelos tradicionales masculinos y, por tanto, está más dispuesto a adoptar nuevas prácticas y puntos de vista originales.

Más dialogante, porque escucha los distintos puntos de vista de los miembros del grupo, para luego tomar la mejor decisión posible. Las mujeres han sido educadas para escuchar, aprender y reflexionar, y utilizan estas herramientas de forma natural en las interacciones del grupo. 
Más dispuesto a compartir información, porque entiende las interconexiones como recursos para mejorar y responder mejor a la realidad.

Las mujeres suelen alentar la participación, y frecuentemente comparten el poder. Esto estimula los grupos donde lideran mujeres, propiciando un clima más positivo y más creativo y una mejor gestión de los conflictos (Medina-Vicent, 2014: 773). Se trata en definitiva, de un liderazgo inclusivo, que está más abierto a recibir ideas y propuestas de otras y otros, y que busca sumar fuerzas e incorporar potencialidades y habilidades. Sin embargo, tiene sus riesgos, como tener menor control sobre los acontecimientos y estar abierto a las críticas, y esto puede suponer conflictos.

En definitiva, hemos de ser conscientes de que la realidad no es tan idílica. Muchas mujeres se adaptan a los modelos masculinos de independencia, control, competición, racionalidad y objetivad para poder continuar con su liderazgo y no ser rechazadas en los ámbitos de poder. Esto supone conflictos entre ellas y críticas a aquellas que proponen modelos de relación diferentes, que son comparadas con las que asumen los modelos masculinos y por eso, rechazadas, criticadas o invisibilizadas.

\subsection{La práctica de los liderazgos}

Para combatir este conflicto entre mujeres es fundamental trazar círculos de mujeres, espacios comunitarios donde poder desarrollar nuestras capacidades y potencialidades, para luego liderar cambios personales y entornos locales. De esta forma se tejen relaciones nuevas, desde la diversidad de la propia subjetividad en interacción con la alteridad de la otra.

\section{a) Trazar círculos igualitarios en la diversidad: todas importan}

Los círculos habilitan a las mujeres para utilizar dos herramientas robadas a lo largo de la historia patriarcal: la memoria y la capacidad de pensar (Barroso, 2007: 183). El círculo es, además de una forma simbólica, un principio político (en el sentido literal de política, la que se hace en la vida cotidiana), que se opone al orden social patriarcal que es vertical y jerárquico. Cuando las mujeres se reúnen y se sientan en círculo la propia ubicación física del círculo nos está dando la pauta de comportamiento. Todas y cada una de las mujeres que se reúnen son iguales, todas pueden hablar con el mismo nivel de autoridad, porque se reconoce su experiencia y se acepta su diversidad (Donoso et al., $2011)$. Unas hablan y otras escuchan y entre todas se interpelan para acompañarse en el proceso de empoderamiento. 
De esta manera se adquiere una visión estratégica que incluye a mujeres y hombres en la construcción de comunidades activas y participativas. La circularidad reestablece el deseo de reaprender a comprender la realidad y a desarrollar nuevos modos de percibirla (Gil, 2011 : 88). Empodera a las mujeres como agentes críticos de la realidad comunitaria y las capacita para ser constructoras de nuevos significados sociales y culturales. La circularidad es la que posibilita la práctica cotidiana de la reciprocidad, de relaciones democráticas y flexibles que evitan la jerarquía y la exclusión. Por último, la circularidad permite experimentar una identidad plural y mestiza, donde las diferencias se gestionan como riqueza y no como amenaza (Brah, 2004: 124-125).

\section{b) Alianzas entre mujeres}

Para que exista intercambio en la diversidad debe haber también voluntad de encuentro. No es fácil considerarse como un colectivo con los mismos intereses siendo conscientes de la diferencia de cada sujeto. Es un desafío poder constituirlo. Las relaciones entre mujeres deben tener un sentido comunitario afectivo y efectivo, tanto en lo social como en lo identitario, para poder aceptar la alteridad de los discursos y desde ahí, encontrar consensos después de haber sido interpelada por su discurso (Eskalera Karacola, 2004: 27).

No es una casualidad que las mujeres hagan pactos cuando se encuentran en lo público. Los pactos protegen y ayudan. Las alianzas establecidas se deben trazar desde criterios de reciprocidad donde quede clara que la diferencia lleva también a un lugar común. La reciprocidad exige apertura, juega con las condiciones para el diálogo, defiende los espacios personales y con ello, reelabora las identidades de las que negocian, reordenando sus intereses y prioridades como una riqueza colectiva que respeta y potencia el espacio propio (Gil, 2011 : 220).

El pacto de mujeres es transgresor para el imaginario fratriarcal, es insurrecto, porque desmonta el mito de que las mujeres no tienen capacidad de organización ni liderazgo. Las alianzas se construyen por tanto desde un «nosotras» en construcción, y no un colectivo preexistente. Así se puede actuar sobre las necesidades y urgencias, derechos y deseos de los sujetos que participan en esa construcción. No existen sujetos definidos para una necesidad única, sino sujetos en proceso que conectan en sus luchas y forman «coaliciones» (en el sentido de la definición de Judith Butler ${ }^{5}$ ) que diseñan y proponen nuevas formas sociales de participación y reivindicación (Gil, 2011: 221). Con ello se mejora la convivencia,

5 Coalición como desarrollo de propuestas políticas de coalición que no presupongas una única categoría «mujeres» sino como encuentros dialógicos que articulan distintas identidades (Butler, 2001: 46). 
se potencia la singularidad, las nuevas subjetividades, y las acciones creativas para los problemas cotidianos. No hay que olvidar la complejidad de este trabajo (Valcárcel, 1997), que implica un esfuerzo de comprensión de las subjetividades femeninas y de sus procesos de desarrollo y empoderamiento. Sin embargo, su práctica, refuerza las búsquedas y derivas personales en cuanto que son compartidas e interpeladas grupalmente a través del respeto y la aceptación.

\section{c) Acompañamiento o mentorización de otras mujeres}

Por último, el pacto entre mujeres lleva a analizar las relaciones intergeneracionales. En los entornos urbanos y mercantilizados se potencia el deseo de independencia como una negación de la necesidad de los otros (Gil, 2011: 224). Se niega la vulnerabilidad y la interdependencia entre seres humanos. Esto sitúa a cada sujeto en una lucha individual por sus derechos como conquista personal y no común y abre la puerta a nuevas sumisiones sociales. Para empoderarse las mujeres necesitan que se tracen relaciones interpersonales con otras mujeres de más experiencia que puedan establecer diálogos de contraste y consejo. Estos diálogos son la consecuencia de asumir una ética de la justicia intergeneracional, que responsabiliza en el cuidado y preparación de las generaciones posteriores para una vida que hay que transformar. La ética de la justicia intergeneracional la podemos definir como el desarrollo de la capacidad de mirar a nuestras hijas y nietas y soñar futuro con ellas y para ellas, donde sean sujetos activos de su propia historia.

Transmitir una herencia multiforme, sororal y centrada en las potencialidades, y no en los condicionamientos, desarrolla prácticas creativas en las nuevas generaciones. De esta forma, lo que el sistema de consumo de la vida individualizado fragmenta y fragiliza, queda de nuevo enlazado a través del mentoring de otras mujeres más jóvenes. Se trata de soñar en futuro más allá de la propia vida. De participar sororalmente en los procesos de empoderamiento de otras mujeres, compartiendo las derivas personales como sustrato de construcción identitario de otras. Favorece el aprendizaje sororal y a la vez la diferenciación como clave personal. Aunque esta práctica sea más propia del mundo empresarial que del medio social, lo cierto es que su exportación a las prácticas políticas y sociales cotidianas puede promover el liderazgo de mujeres en espacios sociales, estableciendo lenguajes y dinámicas comunes e igualitarias dentro de la comunidad social (Puleo, 2013: 296).

Los vínculos que se establecen en el acompañamiento entre mentora y mentorizada, ejercen sobre las mujeres jóvenes un movimiento de su singularidad saludable, que les permite analizar, criticar y derribar muchas de las barreras del imaginario mercantil y patriarcal actual, 
y a superar aquellos elementos del propio sistema fragmentario que pretende convencerlas de que la igualdad se ha conseguido ya y no es necesario luchar ni por la igualdad ni por la propia identidad. En definitiva, la mentorización o acompañamiento de mujeres jóvenes recorta la soledad en las luchas de las mujeres y mejora las redes de sororidad entre mujeres como caminos adecuados para la transformación social (Puleo, 2013: 299), no como una relación jerárquica, sino como un aprendizaje colectivo donde todas tienen algo que aportar.

\section{Prácticas de liderazgos desde lo potencial y lo nómada. Conclusiones.}

Hemos visto que los procesos de empoderamiento de las mujeres desencadenan liderazgos, no sólo en los espacios políticos invisibles como alternativa a las categorías de las fratriarquías sociales, sino que refuerza los liderazgos de mujeres en la política de participación social cotidiana, sin negar el hecho diferencial de cada mujer, en su propia subjetividad.

En este sentido, solo puede emerger autoridad femenina en las interacciones sociales si se produce, a través de los liderazgos creativos, una apropiación de espacios e identidades (Alexander y Tapalde, 2004: 143), no de forma definitiva, sino como cartografías nómadas de la organización social. Es decir, que se construyan espacios de participación y decisión de mujeres y hombres donde, no solo se den nuevos modos de organización (Alexander y Tapalde, 2004: 148), sino que se reconozcan y acepten las transformaciones que producen las luchas cotidianas en la propia política de liderazgo. La aceptación de la vulnerabilidad y fragilidad del sujeto diferenciado que me interpela nos recuerda nuestra condición nómada (Meloni, 2011 : 178), de una cierta diáspora, que nos obliga en cierta manera a confiar en el cultivo de la potencialidad de cada sujeto, no de forma aislada, sino en cooperación sororal en el aquí y ahora.

Este cultivo del ámbito sororal a través los pactos entre mujeres y el acompañamiento o mentorización se convierte en estrategias políticas y educativas en la transformación de sociedades más igualitarias pero más sostenibles. Lo son, en la medida en que sirven para que las mujeres tanto maduras como jóvenes no sólo se apropien de los «no lugares» sociales, sino que desdibujen las fronteras de los círculos sociales a favor de redes interrelacionadas que reduzcan la exclusión de las mujeres en las culturas (Posada, 2002: 336-337).

La sororidad, que en palabras de Marcela Lagarde es una «dimensión ética, política y práctica del feminismo contemporáneo» (Lagarde, 2006: 126), es un crisol de experiencias de mujeres que conduce a la búsqueda de relaciones positivas de empoderamiento y liderazgo de mujeres. Sororidad y empoderamiento están directamente relacionados. Sostiene la 
creación de vínculos, el cuidado de la relación y el acompañamiento personal y grupal entre mujeres.

Por otro lado, del empoderamiento colectivo desde sujetos activos que tratan de constituirse compartiendo su diversidad (Meloni, 2012: 225), emerge la autoridad que insta a la práctica social a tener en cuenta la presencia y acción de las mujeres. Se trata de una autoridad que surge del reconocimiento, del diálogo y de la acción comunitaria. No viene del poder vertical ni de la opresión de unos sobre otros.

Es inevitable, entonces, repensar las relaciones de poder en los liderazgos cotidianos. Desarrollar en las mujeres una nueva cultura del ejercicio del poder a través de relaciones empáticas, que favorezcan el encuentro con el otro en su singularidad. Focalizar el poder en el intercambio con el otro desde sus necesidades y no desde las propias.

Esta dinámica social evita las clasificaciones, aceptando la realidad diversa de las mujeres a la vez que preserva la identidad colectiva que las hace más fuertes en las tensiones frente a los liderazgos excluyentes. De esta manera, la identidad subjetiva armoniza con la colectiva aportando herramientas de autoempoderamiento que se descubren y se comparten con otras mujeres (Lagarde, 2006). Este nomadismo creativo, nos sitúa en una posición de continua búsqueda, desde una conciencia crítica que se resiste a establecerse estáticamente en los códigos de una red social, sino que explora y transgrede constantemente las distintas redes para poder construir estrategias de resistencia a las heteronormatividades fratriarcales. Introduce así, redes u otros elementos novedosos que rompan los códigos de los liderazgos de los hombres con poder (Jasso, 2008: 88-89).

El desarrollo de liderazgos feministas pasa por una des-fronterización del poder en las culturas y sociedades. Construir liderazgos de mujeres que abran puertas. A veces simplemente practicar pequeños huecos en los muros que nos separan y nos excluyen. $Y$, recuperando la historia de Perséfone, Deméter y Hécate también «conspirar» para establecer pactos con los hombres que provoquen emergencias en las formas diferentes de relación y de subjetividad desde marcos comunes de transformación social. Y con ello, ejercitar las prácticas locales de la justicia y la conciliación.

\section{Referencias bibliográficas}

AleXAnder, M. Jaqui y TAlPAde, Chandra (2004): «Genealogías, legados, movimientos», en Las otras inapropiables, Madrid, Traficantes de Sueños, pp. 137-184. 
Barroso, Anabella (2007): « ¿Creer en lo de siempre o como siempre? Creencias cotidianas de las mujeres de iglesia», en $M^{a}$ Pilar de Miguel (ed.) ¿̇En qué creen las mujeres? Creyendo y creando, Bilbao, Desclée de Brouwer, 143-185.

BRAH, Avtar (2004): «Diferencia, diversidad, diferenciación», en Las otras inapropiables, Madrid, Traficantes de Sueños, pp. 107-136.

BRAIDOTI, Rossi (2005): Metamorfosis. Hacia una teoría materialista del devenir, Madrid, Akal. BRAIDOTt, Rossi (2004): Feminismo, diferencia sexual y subjetividad nómade, Barcelona, Gedisa.

BUtLer, Judith (2001): El género en disputa. El feminismo y la subversión de la identidad, Barcelona, Paidós [1990].

Cardeñoso, Olga (2007): «De la piscología cognitiva a la literatura», en Ma Pilar de Miguel (ed.): ¿̇En qué creen las mujeres? Creyendo y creando, Bilbao, Desclée de Brouwer.

Donoso, Trinidad; FIGUeRA, Pilar y MORENO, María Luisa (2011): «Barreras de género en el desarrollo profesional de la mujer universitaria», en Revista de Educación, № 355, 187-212.

Fernández Guerrero, Olaya (2010): «Mecanismos de la exclusión femenina», en Calvo Sebastián, $M^{a}$ Josefina y GoIcoechea GaOMA, $M^{a}$ Ángeles (eds.): Miradas interdisciplinares para un mundo en igualdad, Logroño, Universidad de la Rioja, pp. 45-60.

Flesher FominaYA, Cristina (2015): «El sentido común, lo «político», el feminismo y el 15M», ENCRUCIJADAS. Revista Crítica de Ciencias Sociale. № 9, 1-12.

Foucault, Michel (1967): «De los espacios otros», enArchitecture, Mouvement, Continuité. $\mathrm{N}^{\circ}$ 5, octubre de 1984, pp. 46-49). Conferencia en el Círculo de Estudios Arquitectónicos (14 de marzo de 1967). Recuperado de http://148.206.107.15/biblioteca_digital/ articulos/7-132-1932qmd.pdf [Consultado el 15/05/2017]

FouCAult, Michel (2010): Obras esenciales, Barcelona, Paidós [1954-78].

Foucault, Michel (2007): El nacimiento de la biopolítica, Buenos Aires, Fondo de Cultura Económica [2004].

Fraser, Nancy y HONNeth, Axel (2006): ¿ Redistribución o reconocimiento? Un debate político filosófico, Madrid, Morata.

García-Mina, Ana y Carrasco Galán, Ma José (2003): Género y desigualdad: la feminización de la pobreza, Madrid, Universidad Pontificia de Comillas.

GIL, Silvia L. (2011): Nuevos feminismos. Sentidos comunes en la dispersión, Madrid, Traficantes de Sueños.

HaRDT, Michael y Negrl, Antonio (2002): Imperio, Barcelona, Paidós Ibérica.

HARCOURT, Wendy (2011): Desarrollo y políticas corporales. Debates críticos en género y desarrollo, Barcelona, Bellaterra. 
HousE, Robert J. (1971): «A path goal theory of leader effectiveness», Administrative Science Quarterly. $N^{\circ} 16$, pp. 321-339.

HOUSE, Robert J. y MiTCheLL, T. R. (1974): «A path goal theory of leadership: Some post hoc and priori tests», en J. HUNT Y L. LARSON (eds.), Contingency approaches to leadership, Carbondale, Southern Illinois University Press.

JASSO, Karla (2008): Arte, tecnología y feminismo: nuevas figuraciones simbólicas, México, Universidad lberoamericana.

Meloni, Carolina (2012): Las fronteras del feminismo. Teorías nómadas, mestizas y postmodernas, Madrid, Fundamentos.

Medina-VICENT, Maria (2014): «Hacia un liderazgo femenino de corte transformacional en la dirección de las organizaciones empresariales», en CASADO, Rosa, FLECHA, Consuelo, Gull, Ana, Martínez, Ma del Rocío, Padilla, Ma Teresa y VÁzQuez, Isabel: Aportaciones a la investigación sobre mujeres y género. $V$ Congreso Universitario Internacional Investigación y Género, Sevilla, SIEMUS, pp. 766-777.

MEDINA-VICENT, Maria (2015): «Role models, mentoring y redes de mujeres profesionales: educar en valores feministas para fomentar liderazgos éticos», Revista lberoamericana de Producción Académica y Gestión Educativa. №3, pp. 1-19.

LAGARDE, Marcela (1996): Género y feminismo: desarrollo humano y democracia, Madrid, Horas y Horas.

LAGARde, Marcela (2000): Claves feministas para la autoestima de las mujeres, Madrid, Horas y Horas.

Lagarde, Marcela (2006): Pacto entre mujeres: sororidad. Aportes para el debate, 123 135. Recuperado de http://www.asociacionag.org.ar/pdfaportes/25/09.pdf [Consultado el 15/05/2017]

PosAdA KUBISSA, Luisa (2002): «Pactos entre mujeres», en Celia Amorós (Dir.) 10 palabras clave sobre mujer, Estella, Verbo Divino, pp. 33 1-365.

Puleo, Alicia (2013): Ecofeminismo para otro mundo posible, Madrid, Cátedra.

RodríGuez, Julio (2006): «El Mentoring en la Empresa», Capital Humano. № 197, 22-24.

Rodríguez Magda, Rosa María (Ed.) (2015): Sin Género de Duda. Logros y desafíos del feminismo hoy, Madrid, Biblioteca Nueva.

Ramos López, M. Amparo (2005): Mujeres y liderazgo. Una nueva forma de dirigir, PUV, Valencia.

RoWLANDS, Jo (1995): «Empowerment examined», Development in practice. Vol. 5, № 2, pp. 101-107. Recuperado de: http://www.jstor.org/stable/4028929 [Consultado el 15/05/2017] 
SÁENZ de la Fuente, Izaskun (2007): «Ni Bridget Jones, ni Kate Reddy, ni «Mujeres desesperadas»», en DE MIGUEL, Ma Pilar (ed.) ¿En qué creen las mujeres? Creyendo y creando, Bilbao, Desclée de Brouwer, pp. 77-1 18.

SHINOdA Bolen, Jean (2004): Millonésimo círculo: como transformarnos a nosotras mismas y al mundo, Kairós, Barcelona.

SHINODA Bolen, Jean (2014): El nuevo movimiento global de las mujeres. Construir círculos para transformar el mundo, Barcelona, Kairós.

VAlCÁrCel, Amelia (1997): La política de las mujeres, Madrid, Cátedra.

ValcárCel, Amelia (2009): El feminismo y el saber de las mujeres. En Molina, E. y S A N Miguel, N. (eds.): Universidad, Género y Desarrollo, Madrid, UAM Ediciones, pp. 17-30.

Vianello, Mino y Caramazza, Elena (2002): Género, espacio y poder: Para una crítica de las Ciencias Políticas, Madrid, Cátedra.

Woolf, Virginia (2003): Un cuarto propio, Madrid, Horas y Horas [1929].

YÁNIZ, Concepción (2007): «¿̇Qué quiero ser de mayor? Creencias para impulsar un estilo de vida», en $M^{a}$ Pilar de Miguel (ed.), ¿En qué creen las mujeres? Creyendo y creando, Bilbao, Desclée de Brouwer, pp. 189- 219. 